\title{
Effects of gestational diabetes mellitus on risk of adverse maternal outcomes: a prospective cohort study in Northwest Ethiopia
}

Achenef Asmamaw Muche ${ }^{1,2^{*}}$, Oladapo O. Olayemi ${ }^{3}$ and Yigzaw Kebede Gete ${ }^{2}$

\begin{abstract}
Background: Gestational diabetes mellitus is a leading medical condition woman encounter during pregnancy with serious short- and long-term consequences for maternal morbidity. However, limited evidence was available on potential impacts of gestational diabetes mellitus using updated international diagnostic criteria on adverse maternal outcomes. Therefore, this study aimed to assess the effects of gestational diabetes mellitus on the risk of adverse maternal outcomes in Northwest Ethiopia.
\end{abstract}

Methods: A prospective cohort study was conducted among pregnant women followed from pregnancy to delivery. Gestational diabetes mellitus status was determined by using a two-hour $75 \mathrm{~g}$ oral glucose tolerance test and based on updated international diagnostic criteria. Multivariable log-binomial model was used to examine the effects of gestational diabetes mellitus on the risk of adverse maternal outcomes.

Results: A total of 694 women completed the follow-up and included in the analysis. Women with gestational diabetes mellitus had a higher risk of composite adverse maternal outcome (ARR=1.58, 95\% Cl: 1.22, 2.04), caesarean delivery ( $A R R=1.67 ; 95 \%: 1.15,2.44$ ), pregnancy induced hypertension ( $A R R=3.32 ; 95 \%: 1.55,7.11$ ), premature rupture of membranes (ARR= 1.83; 95\%: 1.02, 3.27), antepartum hemorrhage (ARR= 2.10; 95\%: 1.11, 3.98) and postpartum hemorrhage (ARR= 4.85; 95\%:2.28, 10.30) compared to women without gestational diabetes mellitus.

Conclusions: Gestational diabetes mellitus increased the risk of adverse maternal outcomes. This implies that maternal care and intervention strategies relating to women with gestational diabetes mellitus should be strengthened.

Keywords: Gestational diabetes mellitus, adverse maternal outcome, pregnancy induced hypertension, premature rupture of membranes, antepartum hemorrhage, postpartum hemorrhage

\section{Background}

Gestational diabetes mellitus (GDM) is defined as "hyperglycemia first detected during pregnancy that is clearly not preexisting or overt diabetes" [1]. It is believed to be the drastically increased prevalence of GDM had a negative impacts on various short- and long-term maternal and neonatal adverse outcomes [2, 3].

\footnotetext{
* Correspondence: ashua2014@gmail.com

${ }^{1}$ Department of Obstetrics and Gynecology, Pan African University Life and Earth Sciences Institute, College of Medicine, University of Ibadan, Ibadan, Nigeria

${ }^{2}$ Department of Epidemiology and Biostatistics, Institute of Public Health, University of Gondar, Gondar, Ethiopia

Full list of author information is available at the end of the article
}

Gestational diabetes mellitus has been associated with an increased risk for pregnancy induced hypertension (PIH) with relative risk ranges from 1.4 to 4.15 [4-9] although some studies suggest that the relation between $\mathrm{PIH}$ and GDM is not well understood [10, 11]. It also increases the rate of cesarean delivery by up to $57.4 \%$ and has a greater impact in cases of obesity and/or previous history of cesarean section [12-18]. The risk of induction of labor ranges from $33-38 \%[13,18-20]$, premature rupture of membranes (PROM) [9, 21-23], antepartum hemorrhage $(\mathrm{APH})[24]$, and postpartum hemorrhage (PPH) were associated with GDM $[2,23]$. To the contrary, other studies showed the absence of significant association between

(c) The Author(s). 2020 Open Access This article is distributed under the terms of the Creative Commons Attribution 4.0 International License (http://creativecommons.org/licenses/by/4.0/) which permits unrestricted use, distribution, and reproduction in any medium, provided you give appropriate credit to the original author(s) and the source, provide a link to the Creative Commons license, and indicate if changes were made. The Creative Commons Public Domain Dedication waiver (http://creativecommons.org/publicdomain/zero/1.0/) applies to the data made available in this article, unless otherwise stated. 
GDM and the severity of the risk for PPH [25] and PIH $[11,26]$. Thus, evidence is inconclusive; the extent to which the observed associations were caused by maternal factors or were confined to their poor socioeconomic conditions, behavioral or lifestyle parameters and lack of health care services was still debatable at the moment.

While the adverse maternal outcomes of women with GDM can be improved by proper antenatal care and positive lifestyle changes [27, 28], the risk for adverse outcomes drastically increased as result of increase in maternal glucose level in the second or third trimester, even within ranges previously considered normal for pregnancy $[29,30]$.

Though, the consequences of GDM on adverse maternal outcomes have been recognized in developed countries with different controversies, there are limited data on the effect of GDM in sub-Saharan Africa (SSA) countries where emphasis to it is low. We have also noted that the aforementioned studies used different diagnostic criteria and thresholds, mainly the old GDM diagnostic criteria that could have either under or overestimated the adverse maternal outcomes caused by GDM. Thus, the overall risk of adverse maternal outcomes on women with GDM remains unclear because studies based on the current GDM diagnostic criteria are limited. Therefore, this study aimed to examine the effects of GDM on adverse maternal outcomes using the current updated diagnostic criteria. In addition, the study considered whether the relationship between GDM and adverse maternal outcomes was mediated by lifestyle parameters, such as levels of physical activity and dietary diversity and the extent was affected by the presence of antenatal depression.

\section{Methods and Materials}

\section{Study area and period}

The study was conducted at selected public health facilities of Gondar town (the University of Gondar Comprehensive Specialized Hospital (UoGCSH) and Gondar, Woleka, Maraki, Azezo Health Centers) from March 30, 2018 to March 26, 2019. Gondar town is located in Northwest Ethiopia $747 \mathrm{~km}$ from Addis Ababa (the capital of Ethiopia) and $170 \mathrm{~km}$ from Bahirdar (the capital of the Amhara regional state). According to the 2014 Central Statistical Agency (CSA) population projection, the town had a total population of 306, 246, of whom 149, 970 were men and 156, 276 women [31]. The area is predominantly urban and the town has one public referral hospital, eight health centers, and 15 private clinics.

\section{Study design and population}

A prospective cohort study was conducted on a group of pregnant women recruited at the ANC clinics of the selected health facilities of Gondar town and followed from pregnancy to delivery. Pregnant women were recruited and followed if they were aged 18 years and above, had gestational age of $20-23^{+6}$ weeks with a singleton pregnancy, was permanent resident in the study area, were willing to take routine ANC services and had planned to deliver at one of the selected facilities of the town. We excluded women who had pre-existing or overt diabetes or other medical illness and chronic diseases or were on medication that might affect their glucose metabolism (steroids, $\beta$ adrenergic agonists, anti-psychotic drugs), and/or severely ill at commencement.

\section{Sample size and sampling procedure}

Sample size was estimated using Epi Info 7 software [32] with the following parameters: confidence level of $95 \%$ (2-sided), power of $80 \%$, exposed to non-exposed ratio of 1:4, prevalence of adverse maternal outcome (preeclampsia) in a non-exposed group (non GDM) of $8.7 \%$ and exposed group (GDM) of $27.7 \%$ [9]. This study also considered design effect of 2, and lost follow-up and non-response rate of $15 \%$. The minimum sample size required for the study was 476, of which 97 were exposed (GDM) and 386 non-exposed women (non-GDM). Initially, for the baseline survey, about 1,110 study participants were recruited at the beginning of the study and a total of 1027 participants completed the GDM screening enrolled for this cohort study to increase the power of the study. A detail of the study sample is provided elsewhere [33].

\section{Data collection procedure}

A pre-tested structured questionnaire prepared in English and translated to Amharic (national and local language) and retranslated to English by public health and language expert was used to collect data during baseline survey. Data also abstracted using checklist from the medical records of pregnant women who gave birth. Moreover, validated tools were implemented to assess dietary diversity [34], physical activities [35], and antenatal depression [36].

Both primary and secondary data (chart review) were used. Data on maternal and socio-demographic variables (age, residence, marital status, level of education, occupational status, average monthly income, last normal menstrual period (LNMP), previous pregnancy complications, medical history), behavioral factors (exposure to alcohol use and coffee intake), lifestyle parameters (dietary diversity and physical activity) and antenatal depression status were collected by midwives in face to face interview during baseline survey. Blood pressure (BP) and mid-upper arm circumference (MUAC) were also measured. 
Data on antepartum (gestational age (early fetal ultrasound result), parity, gravidity, hemoglobin level, blood pressure, urine analysis, APH, co-existing obstetric/medical diseases, complications of pregnancy, sonographic result), intrapartum (duration of labor, types of labor (spontaneous or induced), mode of delivery, and premature rupture of membranes) and postpartum (PPH) were retrieved from medical records and focused antenatal care charts (integrated antenatal, labor, delivery and postnatal care cards) of the pregnant women and documented in the checklist prepared for the purpose.

Universal screening for GDM using a two-hour $75 \mathrm{~g}$ oral glucose tolerance test (OGTT) was performed for all pregnant women at 24-28 weeks of gestational age. Besides, for women who had negative result at regular test (24-28 weeks of gestational age) and had at least one type of risk factors for GDM (pre pregnancy BMI $\geq 30$ $\mathrm{Kg} / \mathrm{m}^{2}$, MUAC $\geq 28 \mathrm{~cm}$, age $\geq 35$ years, previous macrosomia, glycosuria, history of GDM, family history of diabetes, previous poor pregnancy outcome or developed pregnancy-related complications) were repeated the test at 32-36 weeks. The tests were done directly at the respective health facilities of the participants by capillary glucose testing, using a standard plasma-calibrated glucometer (HemoCue Glucose B-201+ (A"ngelholm AB, Sweden)). This procedure adhered to the latest recommendations of the International Federation of Gynecology and Obstetrics (FIGO) initiative on GDM diagnosis for settings where a close-by laboratory or facilities for proper storage and transport of blood samples to a distant laboratory are not available [37].

Pregnant women were categorized based on their GDM status and included in this prospective study. All women received follow up care at their respective health facilities under the standard protocol of GDM diagnosis, management, and care services or the health facility's routine protocol. Participants diagnosed with GDM were immediately referred (linked) to health providers who were experts in their respective public health facilities to get possible management and treatment options. Followups were assured through the health centers and UoGCSH in close collaboration with the experts and data collectors. Lastly, the medical records of pregnant women who gave birth were reviewed and information related to maternal outcomes were documented.

\section{Study variables}

\section{Outcome variables}

Composite adverse maternal outcome was defined as the occurrence of one or more of the following: cesarean delivery, $\mathrm{PIH}$, induced labor, $\mathrm{PROM}, \mathrm{APH}$, and/or $\mathrm{PPH}$. Pregnancy-induced hypertension (PIH) is defined as systolic blood pressure $\geq 140 \mathrm{mmHg}$ and/or diastolic blood pressure $\geq 90 \mathrm{mmHg}$ after 20 weeks of pregnancy [38].
Cesarean delivery is an operative technique by which a fetus is delivered through abdominal and uterine incision [39]. Induction of labor is defined as the process of artificially stimulating the uterus to start labor [40]. Premature rupture of membranes (PROM) refers to a patient who is beyond 37 weeks of gestation and has presented with rupture of membranes (ROM) prior to the onset of labor [40]. Antepartum haemorrhage (APH) is defined as bleeding from or in to the genital tract, occurring during second or third trimesters of pregnancy and prior to the birth of the baby [41]. Postpartum haemorrhage (PPH) is defined as a blood loss of $500 \mathrm{ml}$ or more within 24 hours after birth [42].

\section{Primary exposure variable}

The primary exposure variable for this study was GDM. Its diagnosis was made by using the 2017 American Diabetes Association (ADA) [43] or the 2013 World Health Organization (WHO) [44] or modified International Association of the Diabetes and Pregnancy Study Groups (IADPSG) [45] diagnostic criteria. The diagnosis of GDM is made when one or more of the values of plasma glucose level was met (fasting: $\geq 92 \mathrm{mg} / \mathrm{dL}, 1 \mathrm{~h}$ : $\geq 180$ $\mathrm{mg} / \mathrm{dL} ; 2 \mathrm{~h}: \geq 153 \mathrm{mg} / \mathrm{dL}$ ).

\section{Covariates}

The following comprise independent variables that are theorized to be non-causal risk factors for adverse maternal outcomes. Some variables are also associated with GDM and are included in this study as confounding variables.

Maternal age was categorized as $(<25,25-29,30-34$, and $\geq 35$ years); marital status as (married, single, divorced or widowed); education as (no formal education, primary, secondary and above); employment status as (yes vs no); average monthly income classified using interquartile range ( IQR) as $(<1500,1500-2499,2500$ 3999 , $\geq 4000$ Birr); maternal anemia when the hemoglobin level was below $11 \mathrm{~g} / \mathrm{dl}$ [46] and parity as (nullipara, primipara, multipara). Similarly, mid-upper arm circumference (MUAC) is known to be relatively stable during the course of pregnancy and is highly correlated to pre-pregnancy BMI [47, 48]. Women were categorized according to MUAC where $<28 \mathrm{~cm}$ was considered as normal and $\geq 28 \mathrm{~cm}$ taken to indicate pregestational overweight and/or obesity [49]. Mothers who drank coffee and alcohol daily or sometimes in a week after pregnancy were labeled as having exposure to coffee and alcohol, respectively.

Physical activities in the past one week were assessed using the short form of the International Physical Activity Questionnaire (IPAQ) [35]. Then, data was reported as metabolic equivalents according to IPAQ scoring protocol which categorized women into high, moderate 
and low groups [50, 51]. Likewise, a woman's minimum dietary diversity was assessed by using the Food and $\mathrm{Nu}$ trition Technical Assistance (FANTA) 2016 and ten standardized lists of food items consumed day and night in the past 24 hours. The minimum dietary diversity score (MDDS) was dichotomized and coded as 0 and 1 for respondents who consumed less than five group items and greater than or equal to five items, respectively. Finally, the MDDS was categorized as adequate dietary diversity if the woman consumed five and more food item [34]. Antenatal depression was measured by using the Edinburgh Postnatal Depression Scale (EPDS) screening tool having ten specific questions with four Likert scale response options (most of the time, sometimes, not often, never), scored from 0 to 3 (a higher score indicating more depressive symptoms). We used a cut of point of 13 and above on the scale to identify women with depression $[52,53]$.

\section{Statistical analysis}

Data were entered using Epi Info version 7 and analyzed using Stata 14 software. Descriptive statistics (frequencies, percentage, mean, and standard deviation (SD)) were used to describe participant characteristics. Pearson's chi-square test was employed to compare categorical data between women with GDM and without GDM as well as to examine the distribution of independent variables and each adverse maternal outcome. Independent $\mathrm{t}$-test was also used for the comparison of the mean difference of continuous variables.

Log-binomial model was used to determine the relative risk summary metric for the associations between GDM and adverse maternal outcomes and to control the effect of potential confounders. Separate logbinomial models were tested and presented for each outcome. Variables were included in the multivariable log-binomial model based on literature review and their association with each adverse maternal outcome (p-value $\leq 0.20)$ in the bivariate analysis. Crude relative risk (CRR) was generated in model I. In model II, the adjusted relative risk (ARR) for the associations between GDM and adverse maternal outcomes were determined after controlling for maternal and sociodemographic characteristics. In model III, in addition to model II confounding variables, it was adjusted for lifestyle variables (dietary diversity and physical activity). Model IV was adjusted for all confounding variables in models II and III plus antenatal depression. Variables in each model were mutually adjusted for each other. Moreover, multicollinearity between the variables was checked using the variance inflation factor (VIF). Finally, statistical significance was established at $\mathrm{ARR} \neq 1$ with a 95\% CI and P-value $\leq 0.05$.

\section{Results}

\section{Characteristics of participants}

A total of 1027 women were recruited at the ANC clinic and prospectively followed from pregnancy to delivery. Of those, 694 (67.6\%) pregnant women completed the follow-up. Based on the GDM diagnosis criteria, 121 $(17.4 \%)$ of the pregnant women had GDM, while 573 (82.6\%) were without GDM (Fig. 1). The baseline characteristics of participants who completed the follow up was not statistically different from lost to follow-up participants (Table 1).

From all women who completed the follow-up, the mean age of mothers with GDM and no GDM was 30.9 $(\mathrm{SD} \pm 5.01)$ and $27(\mathrm{SD} \pm 5.04)$ years, respectively. Nearly three-fourths (74.3\%) of the women with GDM and $470(82.1 \%)$ without GDM attended school. Twentyone percent of the exposed (GDM) group and $4.2 \%$ of mothers without GDM had family history of diabetes. Most of the non GDM mothers were nulliparous. A higher proportion of anemia, over weight and / or obesity were observed among women with GDM compared to women with normal glucose level. Moreover, a larger percentage $(58.7 \%)$ of women with GDM reported low level of physical activities than women in normal glucose profile. Besides, $76 \%$ and $25 \%$ of women with GDM experienced inadequate dietary diversity and antenatal depression symptoms, while $48.9 \%$ and $6.8 \%$ of women with normal glucose profile faced such problems, respectively (Table 2).

\section{Incidence of adverse maternal outcomes}

Of the total 694 women, 233 (33.6\%) (95\% CI: 30.5, 37.0) had at least one type of adverse maternal outcome. The proportion of adverse maternal outcome among mothers with and without GDM was $52.9 \%$ and $29.5 \%$, respectively. The overall incidence of cesarean delivery was $18 \%$ (95\% CI: 15.6, 21.8), PIH was 5.3\% (95\% CI: 3.7, 7.1), induction of labor was $13.5 \%$ (95\% CI: 11, 16.1), PROM was $9.9 \%$ (95\% CI: 7.9, 12.2), APH was $7.5 \%$ ( $95 \% \mathrm{CI}$ : 5.5, 9.5), and PPH was 4.9\% ( $95 \% \mathrm{CI}: 3.3,6.5$ ). The incidence of cesarean delivery, $\mathrm{PIH}$, induction of labor, PROM, APH, and PPH was higher among women with GDM compared to those with non- GDM (Fig. 2).

\section{Association of gestational diabetes mellitus with risk of adverse maternal outcomes}

The results of the unadjusted log-binomial model (Model I) showed that maternal age, antenatal depression, employment status (marginally) and GDM were associated with composite adverse maternal outcome (at least one type). In multivariate model II, after adjusting for maternal and socio-demographic variables (maternal age, educational status, employment status, MUAC and GDM), the result showed that only GDM had significant 


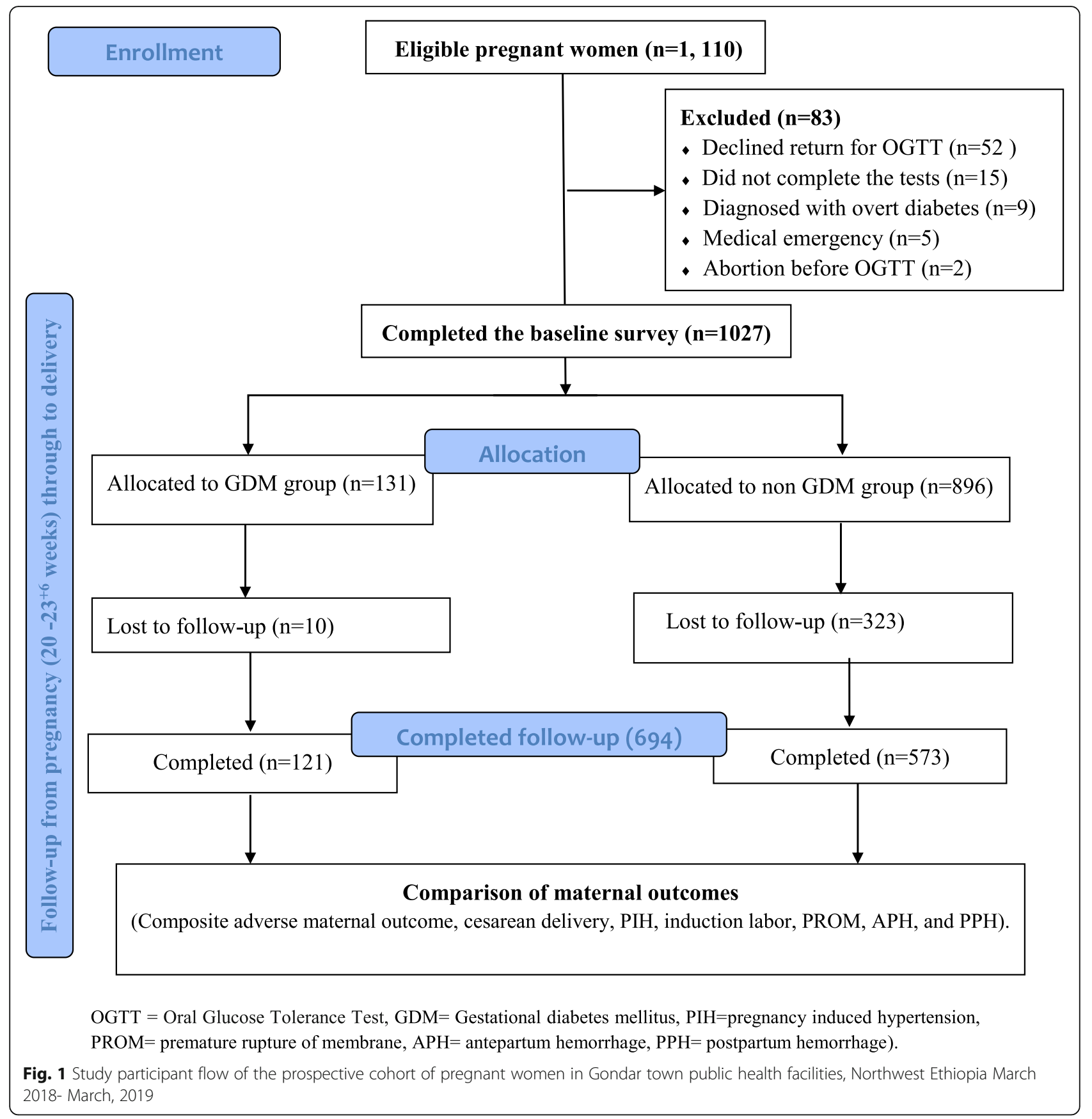

association with composite adverse maternal outcome. We also examined whether the association between maternal and socio-demographic variables and GDM was mediated by the presence of lifestyle parameters (dietary diversity and physical activity) and run a separate multivariate model III with composite adverse maternal outcome. Still GDM was a key risk factor for composite adverse maternal outcome. After controlling for the effects of maternal and socio-demographic characteristics, lifestyle factors (dietary diversity and physical activity), and antenatal depression (Model IV), the association between
GDM and composite adverse maternal outcome remained significant (ARR $=1.58$; 95\% CI: 1.22, 2.04) (Table 3).

Similarly, separate log-binomial models were employed to identify the independent risk of GDM on cesarean delivery, $\mathrm{PIH}$, induction of labor, $\mathrm{PROM}, \mathrm{APH}$, and $\mathrm{PPH}$ (see Additional file 1: Table S1-S6). Overall, after controlling the effects of maternal and socio-demographic characteristics, lifestyle parameters (physical activity and dietary diversity) including antenatal depression (Model IV), the risks of cesarean delivery were higher among women with GDM (ARR=1.67; 95\% CI: 1.15, 2.44), PIH 
Table 1 Comparison between loss to follow-up and the available study participants at Gondar town public health facilities, Northwest Ethiopia: March, 2018-March, 2019 ( $n=1027)$

\begin{tabular}{lll}
\hline variables & Follow up status & $P$ value \\
\cline { 2 - 3 } & $\begin{array}{ll}\text { Available } & \text { Lost to follow up } \\
\mathrm{n}(\%) & \mathrm{n}(\%)\end{array}$ & \\
&
\end{tabular}

Maternal age (years)

$\begin{array}{llll}<25 & 197(28.4) & 126(37.8) & 0.001 \\ 25-29 & 241(34.7) & 125(37.5) & \\ 30-34 & 162(23.3) & 52(15.6) & \\ \geq 35 & 94(13.5) & 30(9)\end{array}$

Marital status

Married

Single and others ${ }^{\mathrm{a}}$

639 (92.1) $\quad 306(91.9)$

Educational level

Not formal education

Primary education

Secondary education

and above

Employment status

Employed

$275(39.6) \quad 131(39.3)$

Unemployed

$$
419(60.4) \quad 202(60.7)
$$

Monthly income (birr)

$<1500$
$1500-2499$
$2500-3999$
$\geq 4000$

$\begin{array}{ll}152(21.9) & 84(25.2) \\ 185(26.7) & 72(21.6) \\ 165(23.8) & 65(19.5) \\ 192(27.7) & 112(33.6)\end{array}$

MUAC

\begin{tabular}{|c|c|c|c|}
\hline MUAC $<28 \mathrm{~cm}$ & $576(83)$ & $276(82.9)$ & 0.964 \\
\hline$M U A C \geq 28 \mathrm{~cm}$ & $118(17)$ & $57(17.1)$ & \\
\hline
\end{tabular}

$\begin{array}{cccc}\text { Normal } & 593(87.1) & 281(85.7) & 0.539 \\ \text { Anemia } & 88(12.9) & 47(14.3) & \\ \text { Parity } & & & \\ \text { Nullipara } & 340(49) & 164(49.2) & 0.373 \\ \text { Primipara } & 180(25.9) & 97(29.1) & \\ \text { Multipara } & 174(25.1) & 72(21.6) & \end{array}$

Previous history of adverse pregnancy outcome ${ }^{c}$

$\begin{array}{llll}\text { Yes } & 151(37.8) & 67(35.6) & 0.621 \\ \text { No } & 249(62.3) & 121(64.4) & \\ \begin{array}{l}\text { Family history of diabetes } \\ \text { Yes }\end{array} & & \\ \text { No } & 50(7.2) & 12(3.6) & 0.023 \\ \text { Alcohol use } & 644(92.8) & 321(96.4) & \\ \text { Yes } & & & \\ \text { No } & 312(45) & 141(42.3) & 0.430 \\ & 382(55) & 192(57.7) & \end{array}$

Table 1 Comparison between loss to follow-up and the available study participants at Gondar town public health facilities, Northwest Ethiopia: March, 2018-March, 2019 (n=1027) (Continued)

\begin{tabular}{|c|c|c|c|}
\hline \multirow[t]{2}{*}{ Variables } & \multicolumn{2}{|c|}{ Follow up status } & \multirow[t]{2}{*}{$P$ value } \\
\hline & $\begin{array}{l}\text { Available } \\
\mathrm{n}(\%)\end{array}$ & $\begin{array}{l}\text { Lost to follow up } \\
\text { n (\%) }\end{array}$ & \\
\hline \multicolumn{4}{|l|}{ Coffee intake } \\
\hline Yes & $484(69.7)$ & $252(75.7)$ & \multirow[t]{2}{*}{0.048} \\
\hline No & $210(30.3)$ & $81(24.3)$ & \\
\hline \multicolumn{4}{|c|}{ Dietary diversity status } \\
\hline Adequate & $322(46.4)$ & $175(52.6)$ & \multirow[t]{2}{*}{0.065} \\
\hline Inadequate & $372(53.6)$ & $158(47.4)$ & \\
\hline \multicolumn{4}{|c|}{ Level of physical activity } \\
\hline High & $208(30.0)$ & $114(34.2)$ & \multirow[t]{3}{*}{0.387} \\
\hline Moderate & $317(45.7)$ & $143(42.9)$ & \\
\hline Low & $169(24.4)$ & $76(22.8)$ & \\
\hline \multicolumn{4}{|c|}{ Antenatal depression } \\
\hline Yes & $70(10.1)$ & $19(5.7)$ & \multirow[t]{2}{*}{0.020} \\
\hline No & $624(89.9)$ & $314(94.3)$ & \\
\hline
\end{tabular}

${ }^{a}=$ Divorced $/$ widowed $^{\mathrm{b}}=18$ participants were missed at base line $(n=1009)$ ${ }^{c}=(n=588)$ MUAC $=$ mid upper arm circumference $\mathrm{cm}=$ centimeter

$(\mathrm{ARR}=3.32 ; 95 \% \mathrm{CI}: 1.55,7.11), \mathrm{PROM}(\mathrm{ARR}=1.83 ; 95 \%$ CI: 1.02, 3.27), APH (ARR= 2.10; 95\% CI: 1.11, 3.98), PPH $(\mathrm{ARR}=4.85 ; 95 \% \mathrm{CI}: 2.28,10.30)$ compared to those without GDM. In this analysis, GDM was not significant risk for induction of labor $(\mathrm{ARR}=1.20 ; 95 \% \mathrm{CI}$ : 0.73, 1.98) (Table 4).

\section{Discussion}

This study was a prospective analysis of 694 women followed from pregnancy to delivery at selected public health facilities of Gondar town, Northwest Ethiopia. We compared the incidence of adverse maternal outcomes on women with and without GDM and examined the independent effects of GDM on adverse maternal outcomes.

The incidence of composite adverse maternal outcome was higher (52.9\%) among women with GDM compared with women without GDM (8.1\%). Specifically, the incidence of caesarean delivery, PIH, PROM, induction of labor, $\mathrm{APH}$, and $\mathrm{PPH}$ was higher among women with GDM than those without GDM. This indicated that GDM can result a higher maternal morbidity. The findings were consistent with those of studies conducted in China [54], Qatar [24], Australia [55], and a review article on LMICs [2].

The multivariable log-binomial model showed that women with GDM had a higher risk for developing the composite adverse maternal outcome by $58 \%$ compared to women who had normal glucose profile. This is in line with studies in East Ethiopia [9], Uganda [56], 
Table 2 Maternal, socio-demographic and life style characteristics of the study participants by GDM status among women completed the follow up from pregnancy through to delivery in Gondar town public health facilities, Northwest Ethiopia March 2018- March, $2019(n=694)$

\begin{tabular}{|c|c|c|c|c|}
\hline \multirow[t]{2}{*}{ Variables } & \multirow{2}{*}{$\begin{array}{l}\text { Total Participants } \\
(n=694)\end{array}$} & \multicolumn{2}{|l|}{ Blood glucose status } & \multirow[t]{2}{*}{$P$ value } \\
\hline & & $\begin{array}{l}\text { GDM } \\
\text { n (\%) }\end{array}$ & $\begin{array}{l}\text { Non-GDM } \\
\text { n (\%) }\end{array}$ & \\
\hline Maternal age (years ) & $27.69 \pm 5.246$ & $30.93 \pm 5.015$ & $27.01 \pm 5.038$ & $<0.001$ \\
\hline$<25$ & $197(28.4)$ & $16(13.2)$ & $181(31.6)$ & $<0.001$ \\
\hline $25-29$ & $241(34.7)$ & $30(24.8)$ & $211(36.8)$ & \\
\hline $30-34$ & $162(23.3)$ & $42(34.7)$ & $120(20.9)$ & \\
\hline$\geq 35$ & $94(13.5)$ & $33(27.3)$ & $61(10.6)$ & \\
\hline \multicolumn{5}{|l|}{ Marital status } \\
\hline Married & $639(92.1)$ & $105(86.8)$ & $534(93.2)$ & 0.018 \\
\hline Single and others ${ }^{a}$ & $55(7.9)$ & $16(13.2)$ & $39(6.8)$ & \\
\hline \multicolumn{5}{|l|}{ Educational level } \\
\hline Not formal education & $134(19.3)$ & $31(25.6)$ & $103(18)$ & 0.032 \\
\hline Primary education & $155(22.3)$ & $32(26.4)$ & $123(21.5)$ & \\
\hline Secondary education and above & $405(58.4)$ & $58(47.9)$ & $347(60.6)$ & \\
\hline \multicolumn{5}{|l|}{ Employment status } \\
\hline Employed & $275(39.6)$ & $62(51.2)$ & $213(37.2)$ & 0.004 \\
\hline Unemployed & $419(60.4)$ & $59(48.8)$ & $360(62.8)$ & \\
\hline Monthly income (birr) & $3169.22 \pm 3167.781$ & $3232.96 \pm 3197.301$ & $3155.76 \pm 3164.162$ & 0.808 \\
\hline$<1500$ & $152(21.9)$ & $29(24)$ & $123(21.5)$ & 0.472 \\
\hline $1500-2499$ & $185(26.7)$ & $26(21.5)$ & $159(27.7)$ & \\
\hline 2500-3999 & $165(23.8)$ & $28(23.1)$ & 137(23.9) & \\
\hline$\geq 4000$ & $192(27.7)$ & $38(31.4)$ & $154(26.9)$ & \\
\hline \multicolumn{5}{|l|}{ Parity } \\
\hline Nullipara & $340(49)$ & $49(40.5)$ & $291(50.8)$ & 0.052 \\
\hline Primipara & $180(25.9)$ & $32(26.4)$ & $148(25.8)$ & \\
\hline Multipara & $174(25.1)$ & $40(33.1)$ & $134(23.4)$ & \\
\hline \multicolumn{5}{|c|}{ Previous history of adverse pregnancy outcome ${ }^{* * *}$} \\
\hline Yes & $151(37.8)$ & $36(45.6)$ & $115(35.8)$ & 0.109 \\
\hline No & $249(62.3)$ & $43(54.4)$ & $206(64.2)$ & \\
\hline \multicolumn{5}{|l|}{ Family history of diabetes } \\
\hline Yes & $50(7.2)$ & $26(21.5)$ & $24(4.2)$ & $<0.001$ \\
\hline No & $644(92.8)$ & $95(78.5)$ & $549(95.8)$ & \\
\hline MUAC & $24.74 \pm 3.139$ & $26.64 \pm 4.074$ & $24.34 \pm 2.745$ & $<0.001$ \\
\hline$M U A C<28 \mathrm{~cm}$ & $576(83)$ & $76(62.8)$ & $500(87.3)$ & $<0.001$ \\
\hline$M \cup A C \geq 28 \mathrm{~cm}$ & $118(17)$ & $45(37.2)$ & $73(12.7)$ & \\
\hline Hemoglobin $(\mathrm{g} / \mathrm{dl})^{\mathrm{b}}$ & $12.666 \pm 1.7575$ & $12.333 \pm 1.7834$ & $12.735 \pm 1.7455$ & 0.024 \\
\hline \multicolumn{5}{|l|}{ Anemic status } \\
\hline Normal & $593(87.1)$ & $96(81.4)$ & $497(88.3)$ & 0.042 \\
\hline Anemia & $88(12.9)$ & 22 (18.6) & $66(11.7)$ & \\
\hline \multicolumn{5}{|l|}{ Alcohol use } \\
\hline Yes & $312(45)$ & $48(39.7)$ & $264(46.1)$ & 0.198 \\
\hline No & $382(55)$ & $73(60.3)$ & 309 (53.9) & \\
\hline
\end{tabular}


Table 2 Maternal, socio-demographic and life style characteristics of the study participants by GDM status among women completed the follow up from pregnancy through to delivery in Gondar town public health facilities, Northwest Ethiopia March 2018- March, 2019 ( $n=694$ ) (Continued)

\begin{tabular}{|c|c|c|c|c|}
\hline \multirow[t]{2}{*}{ Variables } & \multirow{2}{*}{$\begin{array}{l}\text { Total Participants } \\
(n=694)\end{array}$} & \multicolumn{2}{|c|}{ Blood glucose status } & \multirow[t]{2}{*}{$P$ value } \\
\hline & & $\begin{array}{l}\mathrm{GDM} \\
\mathrm{n}(\%)\end{array}$ & $\begin{array}{l}\text { Non-GDM } \\
\mathrm{n}(\%)\end{array}$ & \\
\hline \multicolumn{5}{|l|}{ Coffee intake } \\
\hline Yes & $484(69.7)$ & $82(67.8)$ & $402(70.2)$ & \multirow[t]{2}{*}{0.603} \\
\hline No & $210(30.3)$ & $39(32.2)$ & $171(29.8)$ & \\
\hline \multicolumn{5}{|c|}{ Dietary diversity status } \\
\hline Adequate & $322(46.4)$ & $29(24)$ & $293(51.1)$ & \multirow[t]{2}{*}{$<0.001$} \\
\hline Inadequate & $372(53.6)$ & $92(76)$ & $280(48.9)$ & \\
\hline \multicolumn{5}{|c|}{ Level of physical activity } \\
\hline High & $208(30)$ & $20(16.5)$ & $188(32.8)$ & \multirow[t]{3}{*}{$<0.001$} \\
\hline Moderate & $317(45.7)$ & $30(24.8)$ & $287(50.1)$ & \\
\hline Low & $169(24.4)$ & $71(58.7)$ & $98(17.1)$ & \\
\hline \multicolumn{5}{|c|}{ Antenatal depression } \\
\hline Yes & $70(10.1)$ & $31(25.6)$ & $39(6.8)$ & \multirow[t]{2}{*}{$<0.001$} \\
\hline No & $624(89.9)$ & $90(74.4)$ & $534(93.2)$ & \\
\hline
\end{tabular}

GDM Gestational diabetes mellitus $^{\mathrm{a}}=$ Divorced or widowed $^{\mathrm{b}}=$ participants with hemoglobin data $(n=681)$

$c^{c}=$ participants with prior history of pregnancy $(n=400)$ MUAC=mid upper arm circumference $\mathrm{cm}=$ centimeter

Zimbabwe [57], Canada [17], and Saudi Arabia [58]. So, we can deduce that GDM is a serious problem with a significant impact on maternal outcomes. Thus, there is need to improve access to standard intervention measures to alleviate the plight of women with GDM.

We found the risk of cesarean delivery was higher among pregnant women with GDM than women without GDM by 67\%. Previous studies [59-61] also demonstrated that the risk for cesarean delivery was high among GDM patients. For instance, GDM increased the incidence of cesarean sections (CS) from $30 \%$ [13] to 35\% [62]. Though GDM alone is not an indication for CS before 38 weeks of gestation, it becomes evident that CS is a priority choice for many

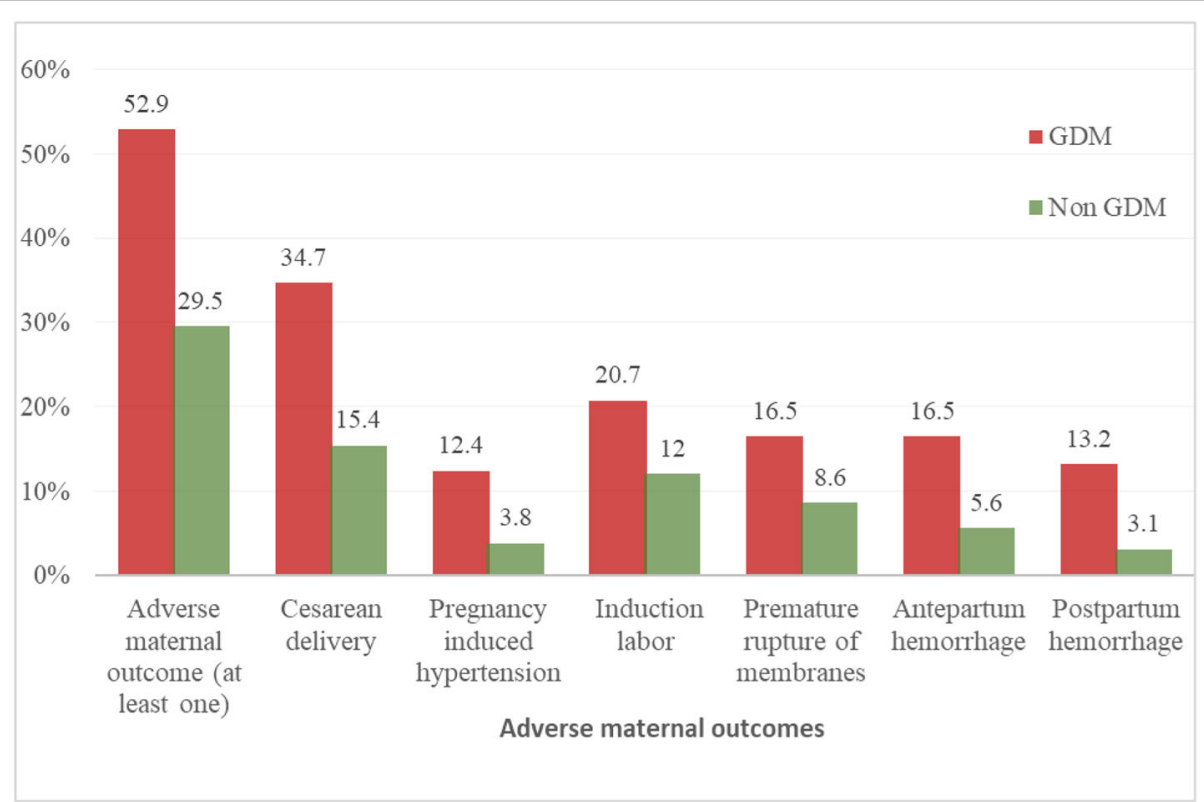

Fig. 2 Adverse maternal outcomes among mothers with and without GDM among women completed the follow up from pregnancy through to delivery in Gondar town public health facilities, Northwest Ethiopia March 2018- March, $2019(n=694)$ 
Table 3 Log-binomial regression analysis (models I-IV) showing the effect of gestational diabetes mellitus on composite adverse maternal outcomes among women completed the follow up from pregnancy through to delivery in Gondar town public health facilities, Northwest Ethiopia March 2018- March, 2019 ( $n=694)$

\begin{tabular}{|c|c|c|c|c|c|c|}
\hline \multirow[t]{2}{*}{ Variables } & \multicolumn{2}{|c|}{$\begin{array}{l}\text { Composite adverse maternal } \\
\text { outcome }\end{array}$} & \multirow{2}{*}{$\begin{array}{l}\text { Model I } \\
\text { CRR }(95 \% \mathrm{Cl})\end{array}$} & \multirow{2}{*}{$\begin{array}{r}\text { Model II } \\
\text { ARR }(95 \% \mathrm{Cl})\end{array}$} & \multirow{2}{*}{$\begin{array}{r}\text { Model III } \\
\text { ARR }(95 \% \text { CI) }\end{array}$} & \multirow{2}{*}{$\begin{array}{r}\text { Model IV } \\
\text { ARR }(95 \% \mathrm{Cl})\end{array}$} \\
\hline & Yes, n (\%) & No, n (\%) & & & & \\
\hline \multicolumn{7}{|l|}{ GDM } \\
\hline Yes & $64(52.9)$ & $57(47.1)$ & $1.79(1.45,2.21)^{* * *}$ & $1.71(1.36,2.14)^{* * *}$ & $1.70(1.33,2.17)^{* * *}$ & $1.58(1.22,2.04)^{* * *}$ \\
\hline No & 169 (29.5) & $404(70.5)$ & 1 & 1 & 1 & 1 \\
\hline \multicolumn{7}{|l|}{ Maternal age (years ) } \\
\hline$<25$ & $54(27.4)$ & $143(72.6)$ & 1 & 1 & 1 & 1 \\
\hline $25-29$ & $82(34)$ & $159(66)$ & $1.24(0.93,1.65)$ & $1.24(0.94,1.65)$ & $1.24(0.94,1.65)$ & $1.23(0.93,1.63)$ \\
\hline $30-34$ & $59(36.4)$ & $103(63.6)$ & $1.33(0.98,1.80)$ & $1.22(0.89,1.67)$ & $1.22(0.90,1.67)$ & $1.23(0.90,1.68)$ \\
\hline$\geq 35$ & $38(40.4)$ & $56(59.6)$ & $1.47(1.06,2.06) *$ & $1.32(0.94,1.85)$ & $1.32(0.94,1.85)$ & $1.35(0.96,1.89)$ \\
\hline \multicolumn{7}{|l|}{ Educational level } \\
\hline Not formal education & $37(27.6)$ & $97(72.4)$ & 1 & 1 & 1 & 1 \\
\hline Primary education & $54(34.8)$ & $101(65.2)$ & $1.26(0.89,1.79)$ & $1.33(0.94,1.87)$ & $1.33(0.94,1.88)$ & $1.34(0.95,1.88)$ \\
\hline Secondary education and above & $142(35.1)$ & $263(64.9)$ & $1.27(0.94,1.72)$ & $1.32(0.96,1.80)$ & $1.32(0.96,1.81)$ & $1.31(0.96,1.80)$ \\
\hline \multicolumn{7}{|l|}{ Employment status } \\
\hline Employed & $104(37.8)$ & $171(62.2)$ & $1.23(1.00,1.51)$ & $1.07(0.86,1.34)$ & $1.08(0.86,1.34)$ & $1.09(0.88,1.36)$ \\
\hline Unemployed & $129(30.8)$ & $290(69.2)$ & 1 & 1 & & 1 \\
\hline \multicolumn{7}{|l|}{ MUAC } \\
\hline $\mathrm{MUAC}<28 \mathrm{~cm}$ & $187(32.5)$ & $389(67.5)$ & 1 & 1 & 1 & 1 \\
\hline$M U A C \geq 28 \mathrm{~cm}$ & $46(39)$ & $72(61)$ & $1.20(0.93,1.55)$ & $1.05(0.82,1.36)$ & $1.06(0.82,1.37)$ & $1.05(0.81,1.36)$ \\
\hline \multicolumn{7}{|l|}{ Dietary diversity status } \\
\hline Adequate & $103(32)$ & $219(68)$ & 1 & & 1 & 1 \\
\hline Inadequate & $130(34.9)$ & $242(65.1)$ & $1.09(0.88,1.35)$ & & $1.01(0.82,1.25)$ & $0.94(0.83,1.27)$ \\
\hline \multicolumn{7}{|l|}{ Level of physical activity } \\
\hline High & $66(31.7)$ & $142(68.3)$ & 1 & & 1 & 1 \\
\hline Moderate & 101(31.9) & $216(68.1)$ & $1.01(0.78,1.30)$ & & $0.95(0.74,1.23)$ & $0.94(0.73,1.21)$ \\
\hline Low & $66(39.1)$ & $103(60.9)$ & $1.23(0.94,1.62)$ & & $0.98(0.73,1.30)$ & $1.00(0.75,1.33)$ \\
\hline \multicolumn{7}{|l|}{ Antenatal depression } \\
\hline Yes & $34(48.6)$ & $36(51.4)$ & $1.52(1.17,1.99)^{* *}$ & & & $1.28(0.97,1.68)$ \\
\hline No & 199 (31.9) & $425(68.1)$ & 1 & & & 1 \\
\hline
\end{tabular}

obstetricians due to different maternal and fetal complications arising from GDM [15]. Despite evidences showing the benefits of vaginal delivery, CS has been preferred for most diabetic pregnant women with previous operations for fear of the rupture of the uterus that may be associated with the risk of fetal macrosomia $[63,64]$. Additionally, a study in Uganda [56] revealed that the modes of delivery were similar, but genital injuries were more common among women with GDM [56]. The primary indications of CS might be fetal macrosomia that resulted from GDM. On the other hand, CS can prevent poor obstetric outcomes and be a life-saving procedure for both the mother and the fetus [65]. However, there is a growing concern about unnecessary CS that leads to risks for maternal morbidity, neonatal death and neonatal admissions into intensive care units [66].

Women with GDM were three times at high risk for $\mathrm{PIH}$ compared to their counter parts. The finding was consistent with several other studies [4-9, 18, 67] which reported that GDM increased the incidence of PIH. Similarly, another study done in Eastern Ethiopia revealed that mothers who had GDM were three times 
Table 4 Summary of Log-binomial regression analysis (models I-IV) showing the effect GDM on adverse maternal outcomes (each type) among women completed the follow up from pregnancy through to delivery in Gondar town public health facilities, Northwest Ethiopia March 2018- March, 2019 ( $n=694)$

\begin{tabular}{|c|c|c|c|c|c|c|c|c|}
\hline \multirow[t]{3}{*}{ Maternal outcome } & \multirow{2}{*}{\multicolumn{2}{|c|}{ Model I }} & \multirow{2}{*}{\multicolumn{2}{|c|}{ Model II }} & \multirow{2}{*}{\multicolumn{2}{|c|}{ Model III }} & \multirow{2}{*}{\multicolumn{2}{|c|}{ Model IV }} \\
\hline & & & & & & & & \\
\hline & CRR $(95 \% \mathrm{Cl})$ & $P$-value & $\operatorname{ARR}(95 \% \mathrm{Cl})$ & $P$ value & $\operatorname{ARR}(95 \% \mathrm{Cl})$ & $P$ value & $\operatorname{ARR}(95 \% \mathrm{Cl})$ & $P$ value \\
\hline Composite adverse maternal outcome & $1.79(1.45,2.21)$ & $<0.001$ & $1.71(1.36,2.14)$ & $<0.001$ & $1.70(1.33,2.17)$ & $<0.001$ & $1.58(1.22,2.04)$ & 0.001 \\
\hline Cesarean delivery & $2.26(1.66,3.08)$ & $<0.001$ & $2.30(1.59,3.34)$ & $<0.001$ & $2.29(1.50,3.50)$ & $<0.001$ & $1.67(1.15,2.44)$ & 0.007 \\
\hline Pregnancy induced hypertension & $3.23(1.73,6.04)$ & $<0.001$ & $3.19(1.67,6.11)$ & 0.000 & $2.99(1.44,6.20)$ & 0.003 & $3.32(1.55,7.11)$ & 0.002 \\
\hline Labor induction & $1.72(1.13,2.59)$ & 0.010 & $1.52(0.97,2.38)$ & 0.065 & $1.40(0.86,2.28)$ & 0.175 & $1.20(0.73,1.98)$ & 0.478 \\
\hline Premature rupture of membranes & $1.93(1.19,3.13)$ & 0.007 & $1.92(1.15,3.22)$ & 0.013 & $1.86(1.05,3.27)$ & 0.033 & $1.83(1.02,3.27)$ & 0.043 \\
\hline Antepartum hemorrhage & $2.96(1.75,4.99)$ & $<0.001$ & $2.91(1.65,5.12)$ & $<0.001$ & $2.25(1.20,4.20)$ & 0.011 & $2.10(1.11,3.98)$ & 0.022 \\
\hline Postpartum hemorrhage & $4.21(2.21,8.02)$ & $<0.001$ & $4.69(2.47,8.87)$ & $<0.001$ & $4.34(2.06,9.13)$ & $<0.001$ & $4.85(2.28,10.30)$ & $<0.001$ \\
\hline
\end{tabular}

CRR Crude relative risk, ARR Adjusted relative risk, $\mathrm{Cl}$ Confidence interval

Notes: Model I: shows crude relative risk. Model II: Adjusted for maternal and socio-demographic variables. Model III: Adjusted for maternal/socio-demographic variables plus life style variables (dietary diversity and physical activity). Model IV: Adjusted for maternal/socio demographic variables, life style variables (dietary diversity and physical activity) plus antenatal depression.

more likely to develop preeclampsia than women who had not [9]. The association might be due to the nature of co-existing mutual risk factors, such as obesity, advanced maternal age and family history of diabetes and hypertension [68]. To maintain stable blood glucose levels, $\beta$ cells in the pancreas subsequently increase the production of insulin, which results in hyperinsulinemia [69]. Evidence suggests that insulin resistance contribute to sodium retention and vasoconstriction in the pathogenesis of hypertensive disorders during pregnancy [70-73]. A better understanding of the association between these conditions may lead to implement more effective strategies on mutual risk factors during prenatal care.

Although the incidence of induction of labor was higher $(20.7 \%)$ among women with GDM than women with normal glucose profile (12\%), the adjusted analysis (model IV) showed no significant difference (ARR $=1.20$; 95\% CI: 0.73, 1.98). This is in line with a study conducted in Australia [55]. Evidence revealed that induction of labor was advised for women who had GDM to decrease further complication associated during delivery $[74,75]$. On the other hand, this study identified antenatal depression increased the risk for the induction of labor by nearly two folds (ARR $=1.85$; 95\% CI: 1.15, 2.98). This finding suggests majority of induced labor perhaps due to stress. Studies also indicated that some healthcare providers encouraged women to elective induction due to the fear of complications of GDM [76-79]. Hence, psychosocial interventions were recommended to antenatal depression and subsequently reduced the risk of induction of labor.

This study also identified that mothers with GDM had more risk for PROM compared to women without GDM. Other studies demonstrated that there was a direct relationship between GDM and PROM [9, 80-83]. This might be due to the secondary complications of polyhydraminos and macrosomic babies caused by GDM and leads the head of the fetus to be arrested at the pelvic inlet, and the entire force exerted by the uterus is directed to the portion of membranes in contact with the internal os. Thus, early rupture of membranes is more likely to occur [23, 84].

In addition, this study found that the risk of APH was two times higher among women who had GDM than among those without GDM. The finding was in line with studies conducted in Ethiopia [9] and Qatar [24]. It might be because GDM has a negative effect on placenta previa and abruption placentae leading to APH. Similarly, we noted that women with GDM were nearly five times at increased risk for PPH than women without GDM. Previous studies [85-87] indicated that there was a strong association between GDM and PPH. This might be due to complications of GDM, such as fetal macrosoma or large for gestational age, shoulder dystocia, birth trauma and operative deliveries subsequently increased the risk for PPH [88]. The study suggested that due attention should be given to the management of obstetric hemorrhage among women with GDM.

The strengths of our study included its prospective nature and using the updated diagnostic criteria of GDM. However, several limitations have been noted. Firstly, it has significant drop-out rate or loss to follow-up. Secondly, the evidence does not show the difference in risks of adverse maternal outcomes based on the types of GDM treatment. Thirdly, stratified analysis was no conducted based on the time of exposure due to very small cases identified at late gestational age.

\section{Conclusions}

The incidence of adverse maternal outcomes was higher among women with GDM than and among 
those without GDM. After controlling the confounders, GDM independently increased the risk of composite adverse maternal outcome, caesarean delivery, pregnancy induced hypertension, premature rupture of membranes, antepartum hemorrhage, and postpartum hemorrhage. This indicates that GDM is a serious problem with a great impact on pregnancy outcomes. Thus, we recommend enhancements of maternal care and intervention strategies for women with GDM to reduce these life-threatening obstetric complications and improve maternal outcomes. Further studies on the treatment, long-term and inter-generational effects of GDM are suggested.

\section{Supplementary information}

Supplementary information accompanies this paper at https://doi.org/10. 1186/s12884-020-2759-8.

\section{Additional file 1: Table S1. Log-binomial regression analysis (models}

I-IV) showing the effect of gestational diabetes mellitus on cesarean delivery among women completed the follow up from pregnancy through to delivery in Gondar town public health facilities, Northwest Ethiopia March 2018- March, 2019 ( $n=694)$. Table S2. Log-binomial regression analysis (models I-IV) showing the effect of gestational diabetes mellitus on pregnancy induced hypertension (PIH) among women completed the follow up from pregnancy through to delivery in Gondar town public health facilities, Northwest Ethiopia March 2018March, 2019 ( $n=694)$. Table S3. Log-binomial regression analysis (models I-IV) showing the effect of gestational diabetes mellitus on labor induction among women completed the follow up from pregnancy through to delivery in Gondar town public health facilities, Northwest Ethiopia March 2018- March, 2019 ( $n=694)$. Table S4. Log-binomial regression analysis (models I-IV) showing the effect of gestational diabetes mellitus on premature rupture of membranes (PROM) among women completed the follow up from pregnancy through to delivery in Gondar town public health facilities, Northwest Ethiopia March 2018March, 2019 ( $n=694)$. Table S5. Log-binomial regression analysis (models I-IV) showing the effect of gestational diabetes mellitus on antepartum hemorrhage (APH) among women completed the follow up from pregnancy through to delivery in Gondar town public health facilities, Northwest Ethiopia March 2018- March, 2019 ( $n=694)$

Table S6. Log-binomial regression analysis (models I-IV) showing the effect of gestational diabetes mellitus on postpartum hemorrhage (PPH) among women completed the follow up from pregnancy through to delivery in Gondar town public health facilities, Northwest Ethiopia March 2018- March, 2019 ( $n=694)$.

\section{Abbreviations}

APH: Antepartum hemorrhage; ARR: Adjusted relative risk; Cl: Confidence interval; CS: Caesarean section; EDPS: Edinburgh postnatal depression scale; FANTA: Food and nutrition technical assistance; FPG: Fasting plasma glucose; GDM: Gestational diabetes mellitus; IPAQ: International physical activity questionnaire; LMIC: Low and middle-income countries; MDDS: Minimum dietary diversity score; MUAC: Mid-upper arm circumference; OGTT: Oral glucose tolerance test; PIH: Pregnancy induced hypertension; PPH: Postpartum hemorrhage; PROM: Premature rupture of membranes; WHO: World health organization

\section{Acknowledgements}

We would also like to forward our sincere gratitude to the African Union Commission (AU) for funding this study, the Pan African University Life and Earth Science Institute (PAULESI), and University of Ibadan (UI) for hosting the program and University of Gondar. We would also like to acknowledge the Setema Limited PLC for their material support (Hemocue Glucose 201 with micro cuvette). We appreciate Dr. Mulat Adefris (Associate professor of
Obstetrics and Gynecology) at the University of Gondar for his professional assistant and Mr. Demeke Dessu of the University of Gondar for language editing assistance. Last but not least, we would like to extend our thanks to all data collectors, experts in the selected health facilities and study participants who participated in the study.

\section{Authors' contributions}

AAM conceived and designed the study, analyzed the data and prepared the manuscript. OO \& YKG assisted the development of the research idea, the analysis, interpretation and preparation of the manuscript. All authors read and approved the final manuscript

\section{Funding}

This study was supported by the Pan African University (PAU), a continental initiative of the African Union Commission (AU), Addis Ababa, Ethiopia, as part of the Ph.D. Fellowship Program in Reproductive Health Sciences. AAM received the funding from $P A U$. The funder had no any role in design of the study, data collection, analysis, interpretation of the data and preparation of the manuscript.

\section{Availability of data and materials}

The datasets used and/or analyzed during the current study are available from the corresponding author on reasonable request.

\section{Ethics approval and consent to participate}

The study was conducted after ethical approval was obtained from the Institute for Advanced Medical Research and Training (IAMRAT), College of Medicine, University of Ibadan, Ibadan, Nigeria with the I/UCH EC Registration Number of NHREC/05/01/2008a and UI/UCH Ethics Committee assigned number of UI/EC/17/0435 and the Institutional Review Board (IRB) of the University of Gondar (Ref.No; ON/P/RCS/05/811/2018). Permission from the Amhara Public Health Institute and the health authorities of the study sites was also received prior to the start of the study. All participants provided (written or thumb-printed) informed consent. The collected information during the course of the research was treated with the utmost confidentiality.

\section{Consent for publication}

Not applicable

\section{Competing interests}

The authors declared that they have no competing interests.

\section{Author details}

${ }^{1}$ Department of Obstetrics and Gynecology, Pan African University Life and Earth Sciences Institute, College of Medicine, University of Ibadan, Ibadan Nigeria. ${ }^{2}$ Department of Epidemiology and Biostatistics, Institute of Public Health, University of Gondar, Gondar, Ethiopia. ${ }^{3}$ Department of Obstetrics and Gynecology, College of Medicine, University College Hospital, University of Ibadan, Ibadan, Nigeria.

Received: 12 November 2019 Accepted: 22 January 2020

Published online: 03 February 2020

\section{References}

1. World Health Organization (WHO). Diagnostic criteria and classification of hyperglycaemia first detected in pregnancy. World Health Organization: 2013

2. Wang Z, Kanguru L, Hussein J, Fitzmaurice A, Ritchie K. Incidence of adverse outcomes associated with gestational diabetes mellitus in low-and middleincome countries. Int J Gynecol Obstet. 2013;121(1):14-9.

3. Roglic G. Diabetes in women: the global perspective. Int J Gynecol Obstet. 2009:104:S11-S3.

4. Casey BM, Lucas MJ, McIntire DD, Leveno KJ. Pregnancy outcomes in women with gestational diabetes compared with the general obstetric population. Obstet Gynecol. 1997;90(6):869-73.

5. Joffe GM, Esterlitz JR, Levine RJ, Clemens JD, Ewell MG, Sibai BM, et al. The relationship between abnormal glucose tolerance and hypertensive disorders of pregnancy in healthy nulliparous women. Am J Obstet Gynecol. 1998;179(4):1032-7. 
6. Yogev $Y$, Xenakis EM, Langer $O$. The association between preeclampsia and the severity of gestational diabetes: the impact of glycemic control. Am J Obstet Gynecol. 2004;191(5):1655-60.

7. Suhonen L, Teramo K. Hypertension and pre-eclampsia in women with gestational glucose intolerance. Acta Obstet Gynecol Scand. 1993;72(4):269-72

8. Conde-Agudelo A, Belizán JM. Risk factors for pre-eclampsia in a large cohort of Latin American and Caribbean women. BJOG: Int J Obstet Gynaecol. 2000;107(1):75-83.

9. Wakwoya EB, Fita FU. Adverse maternal outcome and its association with gestational diabetes among women who gave birth in selected public hospitals in Eastern Ethiopia. Trop J Obstet Gynaecol. 2018;35(1): 58-62.

10. Jensen DM, Sørensen B, Feilberg-Jørgensen N, Westergaard J, Beck-Nielsen H. Maternal and perinatal outcomes in 143 Danish women with gestational diabetes mellitus and 143 controls with a similar risk profile. Diabetic Med. 2000;17(4):281-6.

11. Jacobson JD, Cousins L. A population-based study of maternal and perinatal outcome in patients with gestational diabetes. Am J Obstet Gynecol. 1989; 161(4):981-6.

12. Naylor CD, Sermer M, Chen E, Sykora K. Cesarean delivery in relation to birth weight and gestational glucose tolerance: pathophysiology or practice style? Jama. 1996;275(15):1165-70.

13. Yogev $Y$, Ben-Haroush A, Chen R, Glickman H, Kaplan B, Hod M. Active induction management of labor for diabetic pregnancies at term; mode of delivery and fetal outcome-a single center experience. Eur J Obstet Gynecol Reprod Biol. 2004;114(2):166-70.

14. Saxena P, Tyagi S, Prakash A, Nigam A, Trivedi SS. Pregnancy outcome of women with gestational diabetes in a tertiary level hospital of north India. Soc Med. 2011;36(2):120.

15. Gascho CLL, Leandro DMK. e Silva TR, Silva JC. Predictors of cesarean delivery in pregnant women with gestational diabetes mellitus. Revista Brasileira de Ginecologia e Obstet/RBGO Gynecol Obstet. 2017;39(02):060-5.

16. Abu-Heija AT, Al-Bash M, Mathew M. Gestational and pregestational diabetes mellitus in Omani women: comparison of obstetric and perinatal outcomes. Sultan Qaboos University Med J. 2015;15(4):e496.

17. McMahon M, Ananth C, Liston R. Gestational diabetes mellitus. Risk factors, obstetric complications and infant outcomes. J Reprod Med. 1998;43(4):372-8.

18. Gasim T. Gestational diabetes mellitus: maternal and perinatal outcomes in 220 Saudi women. Oman Med J. 2012:27(2):140.

19. Peticca P, Keely EJ, Walker MC, Yang Q, Bottomley J. Pregnancy outcomes in diabetes subtypes: how do they compare? A province-based study of Ontario, 2005-2006. J Obstet Gynaecol Canada. 2009;31(6):487-96.

20. Tan PC, Ling LP, Omar SZ. The 50-g glucose challenge test and pregnancy outcome in a multiethnic Asian population at high risk for gestational diabetes. Int J Gynecol Obstet. 2009;105(1):50-5.

21. Köck K, Köck F, Klein K, Bancher-Todesca D, Helmer H. Diabetes mellitus and the risk of preterm birth with regard to the risk of spontaneous preterm birth. J Maternal-Fetal Neonatal Med. 2010;23(9):1004-8.

22. Bhat M, Ramesha K, Sarma SP, Menon S, Kumar SG. Outcome of gestational diabetes mellitus from a tertiary referral Center in South India: a casecontrol study. J Obstet Gynecol India. 2012;62(6):644-9.

23. Kari A, Sahhaf F, Abbasalizadeh F. Maternal, fetal and neonatal outcomes in mothers with diabetes mellitus or gestational diabetes that complicated with preterm premature rupture of the membrane (PPROM). Int J Womens Health Reprod Sci. 2017;5(1):66-71.

24. Bener A, Saleh NM, Al-Hamaq A. Prevalence of gestational diabetes and associated maternal and neonatal complications in a fast-developing community: global comparisons. Int J Women's Health. 2011;3:367-73.

25. Kramer MS, Dahhou M, Vallerand D, Liston R, Joseph K. Risk factors for postpartum hemorrhage: can we explain the recent temporal increase? J Obstet Gynaecol. 2011;33(8):810-9.

26. Cousins L. Pregnancy complications among diabetic women: review 19651985. Obstet Gynecol Surv. 1987;42(3):140-9.

27. Athukorala C, Crowther CA, Willson K. Australian Carbohydrate Intolerance Study in Pregnant Women (ACHOIS) Trial Group. Women with gestational diabetes mellitus in the ACHOIS trial: risk factors for shoulder dystocia. Aust N Z J Gobstet and Gynaecol. 2007:47(1):37-41.

28. Anjana RM, Sudha V, Lakshmipriya N, Anitha C, Unnikrishnan R, Bhavadharini $B$, et al. Physical activity patterns and gestational diabetes outcomes-The wings project. Diab Res Clin Pract. 2016;116:253-62.
29. Metzger BE, Coustan DR, Trimble ER. Hyperglycemia and adverse pregnancy outcomes. Clin chem. 2019;65(7):937-8.

30. Catalano PM, McIntyre HD, Cruickshank JK, McCance DR, Dyer AR, Metzger BE, et al. The Hyperglycemia and Adverse Pregnancy Outcome Study. Assoc GDM Obes Pregnancy Outcomes. 2012;35(4):780-6.

31. Federal Democratic Republic of Ethiopia, Central Statistical Agency,Population Projection of Ethiopia for All Regions At Wereda Level from 2014 - 2017

32. Centers for Disease Control and Prevention (US): introducing epi info.7.

33. Muche AA, Olayemi OO, Gete YK. Prevalence of gestational diabetes mellitus and associated factors among women attending antenatal care at Gondar town public health facilities, Northwest Ethiopia. BMC Pregnancy Childbirth. 2019:19(1):334.

34. Food and Agriculture Organization (FAO), Minimum Dietary Diversity for Women: A Guide for Measurement, Food and Agriculture Organization of the United Nations, USAID's Food and Nutrition Technical Assistance III Project (FANTA), managed by FHI 360, Rome, 2016.

35. Hagströmer M, Oja P, Sjöström M. The International Physical Activity Questionnaire (IPAQ): a study of concurrent and construct validity. Public health Nutr. 2006;9(6):755-62.

36. Murray D, Cox JL. Screening for depression during pregnancy with the Edinburgh Depression Scale (EDDS). J Reprod Infant psychol. 1990;8(2): 99-107.

37. Hod M, Kapur A, Sacks DA, Hadar E, Agarwal M, Di Renzo GC, et al. The International Federation of Gynecology and Obstetrics (FIGO) Initiative on gestational diabetes mellitus: A pragmatic guide for diagnosis, management, and care\#. J K Gynecol Obstet. 2015;131:S173-211.

38. Visintin C, Mugglestone MA, Almerie MQ, Nherera LM, James D, Walkinshaw S. Management of hypertensive disorders during pregnancy: summary of NICE guidance. BMJ (Clinical research ed). 341: 2010, c2207.

39. Tsega F, Mengistie B, Dessie $Y$, Mengesha M. Prevalence of cesarean section in urban health facilities and associated factors in Eastern Ethiopia: hospital based cross sectional study. J Preg Child Health. 2015;2(3):169-73.

40. Organization $W H$. Education material for teachers of midwifery: midwifery education modules. 2008.

41. Needham J. Antepartum haemorrhage. Managing Childbirth Emergencies in the Community and Low-Tech Settings. 2015;26.

42. World Health Organization (WHO). WHO recommendations for the prevention and treatment of postpartum haemorrhage: World Health Organization; 2012.

43. American Diabetes Association (ADA): Classification and diagnosis of diabetes. Diabetes care. 2017;40(Supplement 1):S11-S24.

44. World Health Organization (WHO). Diagnostic criteria and classification of hyperglycaemia first detected in pregnancy. Available from: http://apps.who. int/iris/bitstream/10665/8597/1/WHO_NMH_MND_13.2_eng.pdf. 2013.

45. International Association of Diabetes and Pregnancy Study Groups (IADPSG). International association of diabetes and pregnancy study groups recommendations on the diagnosis and classification of hyperglycemia in pregnancy. Diab Care. 2010;33(3):676-682.

46. World Health Organization (WHO). Haemoglobin concentrations for the diagnosis of anaemia and assessment of severity. 2011.

47. Gale CR, Javaid MK, Robinson SM, Law CM, Godfrey KM, Cooper C. Maternal size in pregnancy and body composition in children. J Clin Endocrinol Metab. 2007:92(10):3904-11.

48. Ricalde AE. Velásquez-Meléndez G, Tanaka ACdA, de Siqueira AA. Mid-upper arm circumference in pregnant women and its relation to birth weight. Revista de saude publica. 1998;32:112-7.

49. Oza-Frank R, Ali MK, Vaccarino V, Narayan KV. Asian Americans: diabetes prevalence across US and World Health Organization weight classifications. Diab Care. 2009;32(9):1644-6.

50. Craig CL, Marshall AL, Sjöström M, Bauman AE, Booth ML, Ainsworth BE, et al. International physical activity questionnaire: 12-country reliability and validity. Med Sci in Sports Exerc. 2003;35(8):1381-95.

51. Ekelund $U$, Sepp H, Brage S, Becker W, Jakes R, Hennings M, et al. Criterionrelated validity of the last 7-day, short form of the International Physical Activity Questionnaire in Swedish adults. Public health nutrition. 2006;9(2): 258-65.

52. Cox JL, Holden JM, Sagovsky R. Detection of postnatal depression. Development of the 10-item Edinburgh Postnatal Depression Scale. Br J Psychiatry. 1987;150(6):782-6. 
53. Dibaba Y, Fantahun M, Hindin MJ. The association of unwanted pregnancy and social support with depressive symptoms in pregnancy: evidence from rural Southwestern Ethiopia. BMC Pregnancy Childbirth. 2013;13(1):135.

54. Yang X, Hsu-Hage B, Zhang H, Yu L, Dong L, Li J, et al. Gestational diabetes mellitus in women of single gravidity in Tianjin City. China Diab Care. 2002; 25(5):847-51.

55. Ju H, Rumbold AR, Willson KJ, Crowther CA. Borderline gestational diabetes mellitus and pregnancy outcomes. BMC Pregnancy Childbirth. 2008;8(1):31

56. Odar E, Wandabwa J, Kiondo P. Maternal and fetal outcome of gestational diabetes mellitus in Mulago Hospital, Uganda. Afr Health Sci. 2004;4(1):9-14.

57. Zvinavashe Mathilda MD, Ndaimani Augustine, Mhlanga Maxwell. Prevalence of Diabetes in Pregnancy At A Tertiary Care Institution And Associated Perinatal Outcomes. J Dent Med Sci (IOSR-JDMS) 16, Issue 12 Ver III (Dec 2017), PP 82-89

58. Gasim T. Gestational Diabetes Mellitus: Maternal and Perinatal Outcomes in 220 Saudi Women. Oman Med J. 2012;27(2):140-4

59. Metzger BE, Contreras M, Sacks D, Watson W, Dooley SL, Foderaro M, et al. Hyperglycemia and adverse pregnancy outcomes. N Engl J Med. 2008; 358(19):1991-2002.

60. Gorgal R, Gonçalves E, Barros M, Namora G, Magalhães Â, Rodrigues T, et al. Gestational diabetes mellitus: A risk factor for non-elective cesarean section. J Obstet Gynaecol Re. 2012;38(1):154-9.

61. Langer O, Rodriguez DA, Xenakis EM, McFarland MB, Berkus MD, Arredondo F. Intensified versus conventional management of gestational diabetes. Am J Obstet Gynecol. 1994;170(4):1036-47.

62. Goldman M, Kitzmiller JL, Abrams B, Cowan RM, Laros RK. Obstetric complications with GDM: effects of maternal weight. Diab. 1991; 40(Supplement 2):79-82.

63. Oliveira TA. Aquino MMAd, Mariani Neto C. Indução do parto em pacientes com cesárea anterior. Femina. 2009;37(8):427-32.

64. Conway $\mathrm{DL}$, Langer $\mathrm{O}$. Elective delivery of infants with macrosomia in diabetic women: reduced shoulder dystocia versus increased cesarean deliveries. Am J Obstet Gynecolo. 1998;178(5):922-5.

65. Souza JP, Gülmezoglu AM, Lumbiganon P, Laopaiboon M, Carroli G, Fawole B, et al. Caesarean section without medical indications is associated with an increased risk of adverse short-term maternal outcomes: the 2004-2008 WHO Global Survey on Maternal and Perinatal Health. BMC Med. 2010;8(1):71.

66. Villar J, Carroli G, Zavaleta N, Donner A, Wojdyla D, Faundes A, et al. Maternal and neonatal individual risks and benefits associated with caesarean delivery: multicentre prospective study. BMJ (Clin Res ed). 2007; 335(7628):1025.

67. Bener A, Saleh NM, Al-Hamaq A. Prevalence of gestational diabetes and associated maternal and neonatal complications in a fast-developing community: global comparisons. Int J women's health. 2011;3:367.

68. Solomon CG, Seely EW. Brief review: hypertension in pregnancy: a manifestation of the insulin resistance syndrome? Hypertension (Dallas, Tex 1979). 2001;37(2):232-9.

69. Katulski K, Czyzyk A, Podfigurna-Stopa A, Genazzani AR, Meczekalski B. Pregnancy complications in polycystic ovary syndrome patients. Gynecol Endocrinol : Official J Int Soc Gynecoll Endocrinology. 2015;31(2):87-91.

70. Jijiwa H, Sabitu A, Danbello Z, Jumba F, Haruna H, AI SS. Hypertension among pregnant women attending GMC Hospital, Ajman, UAE. GMJ, ASM. 2015:4(S2):S47-53.

71. Salzer L, Tenenbaum-Gavish K, Hod M. Metabolic disorder of pregnancy (understanding pathophysiology of diabetes and preeclampsia). Best Pract Res Clin Obstet Gynaecol. 2015;29(3):328-38.

72. Negrato CA, Jovanovic L, Tambascia MA, Geloneze B, Dias A, Calderon Ide $M$, et al. Association between insulin resistance, glucose intolerance, and hypertension in pregnancy. Metab Syndr Relat Disord. 2009;7(1):53-9.

73. Perveen $\mathrm{S}$, Jabeen $\mathrm{Q}$, Iqbal MZ. Relationship between gestational diabetes and pregnancy induced hypertension (PIH). Int Curr Pharm J. 2015;4(11): 453-6.

74. Ram Uma BB, Ranjani H, Mahalakshmi MM, Anjana RM, Unnikrishnan R, Kayal A, Malanda B, Mohan ABV. Pregnancy outcome of gestational diabetes mellitus using a structured model of care : WINGS project (WINGS10). J Obstet Gynaecol Res. 2016

75. Rosenstein MG, Cheng YW, Snowden JM, Nicholson JM, Doss AE, Caughey $A B$. The risk of stillbirth and infant death stratified by gestational age in women with gestational diabetes, American journal of obstetrics and gynecology. 2012;206(4):309.
76. Dekker RL. Labour induction for late-term or post-term pregnancy. Women Birth : J Aust College of Midwives. 2016:29(4):394-8.

77. Simpson KR, Thorman KE. Obstetric "conveniences": elective induction of labor, cesarean birth on demand, and other potentially unnecessary interventions. J Perinat Neonatal Nurs. 2005;19(2):134-44.

78. Johnson R, Slade P. Obstetric complications and anxiety during pregnancy: is there a relationship? J Psychosom Obstet Gynecol. 2003;24(1):1-14.

79. Hanna-Leena MR. Experiences of fears associated with pregnancy and childbirth: a study of 329 pregnant women. Birth (Berkeley, Calif). 2002;29(2): 101-11.

80. Bhat M RK, Sarma SP, Menon S, Ganesh Kumar S. Outcome of gestational diabetes mellitus from a tertiary referral center in South India: a case-control study. J Obstet Gynaecol India 2012;62:644-649 doi:101007/ s13224-0120226-9.

81. Al Riyami NA-RI, Al-Shezaw F, Al-Khabori M. Extreme preterm premature rupture of membranes: risk factors and feto maternal outcomes. Oman Med J. 2013;28:108-11. 105001/omj201328.

82. Boriboonhirunsarn DTP, Sunsaneevithayakul P. Adverse pregnancy outcomes in gestational diabetes mellitus. J Med Assoc Thai. 2006:89:S23-8.

83. Aila Kari FS, Abbasalizadeh F. Maternal, Fetal and Neonatal Outcomes in Mothers With Diabetes Mellitus or Gestational Diabetes That Complicated With Preterm Premature Rupture of the Membrane (PPROM). Int J Women's Health Reprod Sciences. 2017;5(1):66-71.

84. Hamza A, Herr D, Solomayer EF, Meyberg-Solomayer G. Polyhydramnios: Causes. Diagn The. Geburtshilfe Frauenheilkunde. 2013;73(12):1241-6.

85. Michael S, Kramer MD, Vallerand D, Liston R, Joseph KS. Risk Factors for Postpartum Hemorrhage: Can We Explain the Recent Temporal Increase? J Obstet Gynaecol Can. 2011;33(8):810-9.

86. Dittakarn Boriboonhirunsarn M, Talungjit P, Sunsaneevithayakul P. Adverse pregnancy outcomes in gestational diabetes mellitus. J Med Assoc Thai. 2006:89(4):S23-8.

87. Bhavana $\mathrm{G}$, Abhishek M, Suneeta M. A study of risk factors of postpartum hemorrhage and indications for caesarean section. Int J Reprod Contracept Obstet Gynecol. 2016;5(6):2017-21.

88. Chauhan SPHN, Magann EF, Morrison JC, Kenney SP, Devoe LD. Limitations of clinical and sonographic estimates of birth weight: experience with 1034 parturients. Obstet Gynecol. 1998:91(1):72-7.

\section{Publisher's Note}

Springer Nature remains neutral with regard to jurisdictional claims in published maps and institutional affiliations.

Ready to submit your research? Choose BMC and benefit from:

- fast, convenient online submission

- thorough peer review by experienced researchers in your field

- rapid publication on acceptance

- support for research data, including large and complex data types

- gold Open Access which fosters wider collaboration and increased citations

- maximum visibility for your research: over $100 \mathrm{M}$ website views per year

At BMC, research is always in progress.

Learn more biomedcentral.com/submissions 